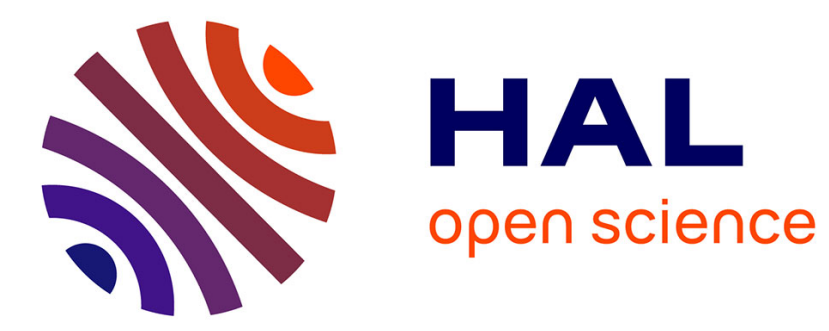

\title{
A versatile fast low noise preamplifier in UHF bipolar technology
}

M. Goyot

\section{To cite this version:}

M. Goyot. A versatile fast low noise preamplifier in UHF bipolar technology. International Conference on New Developments in Photodetection 2, Jun 1999, Beaune, France. pp.374-377. in2p3-00005346

\section{HAL Id: in2p3-00005346 \\ https://hal.in2p3.fr/in2p3-00005346}

Submitted on 12 Apr 2000

HAL is a multi-disciplinary open access archive for the deposit and dissemination of scientific research documents, whether they are published or not. The documents may come from teaching and research institutions in France or abroad, or from public or private research centers.
L'archive ouverte pluridisciplinaire HAL, est destinée au dépôt et à la diffusion de documents scientifiques de niveau recherche, publiés ou non, émanant des établissements d'enseignement et de recherche français ou étrangers, des laboratoires publics ou privés. 


\title{
A VERSATILE FAST LOW NOISE PREAMPLIFIER IN UHF BIPOLAR TECHNOLOGY.
}

\author{
M. Goyot \\ Institut de Physique Nucléaire de Lyon, IN2P3-CNRS et Université Claude Bernard, \\ 43 Boulevard du 11 Novembre 1918, 69622 Villeurbanne cedex, France.
}

\begin{abstract}
A low noise, low power, radiation hard, full custom integrated circuit has been studied in UHF1 Harris process for coupling with photodetectors of the CMS electromagnetic calorimeter. A versatile new version of the prototype preamplifier has been designed with improved performances in terms of noise, dynamic range, and consumption. Experimental results using an avalanche photodiode in DC coupling mode to preamplifier are shown. Irradiations tests have been performed with a Xray generator. Results obtained are given up to 10Mrad $\left(\mathrm{SiO}_{2}\right)$. An upgrade version in UHF1X technology at present in foundry is briefly presented.
\end{abstract}

Keywords: bipolar fast low noise preamplifier

\section{Introduction}

The photosensors which are being adopted for the CMS-ECAL are silicon solid state devices. From 1 or $10 \mathrm{nA}$ in initial conditions, the silicon detectors leakage current of PIN or APD's increases up to 10 microamps or more due to radiation effect. A fast shaping $[1,2]$ is the best solution to optimize signal noise ratio and also to collect data from colliding beams with high interaction rate.

A transimpedance preamplifier configuration ${ }^{[3]}$ is proposed for detectors capacitance in the range of $10 \mathrm{pF}$ to 150pF. The implementation in specific integrated circuit is carried out using Harris Semiconductor UHF1 complementary bipolar process. This dielectrically isolated technology reduces the radiation effect on devices. Experimental results of these prototypes are given. 


\section{Circuits}

The ASIC front-end electronics is subdivised into three separate functions: low noise amplifier, buffer and DC differential amplifier. The preamplifier (figure 1a) is configured with an internal RC network in the feedback loop, $\mathrm{Rf}=39 \mathrm{~K} \Omega$ and $\mathrm{Cf}=0.5 \mathrm{pF}$. The buffer (figure $1 \mathrm{~b}$ ) is a single Widlar boost circuit adaptation. Two differential amplifiers (figure 1c) are included on chip for baseline control.

Power dissipation for the whole circuit at nominal bias voltage is $13 \mathrm{~mW}$. The chip is a part of multiproject organized by $\operatorname{SdM}^{[4]}$.

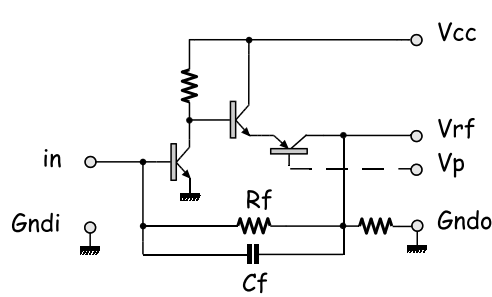

(a)

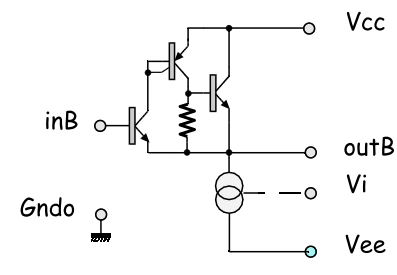

(b)

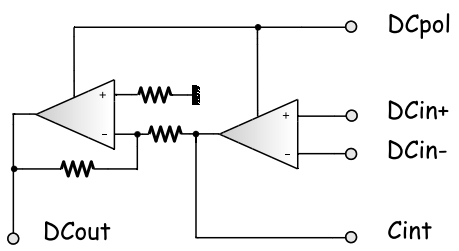

(c)

figure 1: simplified diagram

The integrated circuit chip packaging is shown in figure 2. A 16 pinout ceramic leadless chip carrier is mounted with a minimum of additional components on a kapton multilayer printed circuit board with copper plate $(0.4 \mathrm{~mm}$ thick) to suppress thermal transfer to the detector side (two connections). On the other side, the output signal, bias detector and requirements are transmitted by kapton flex to level 2 .

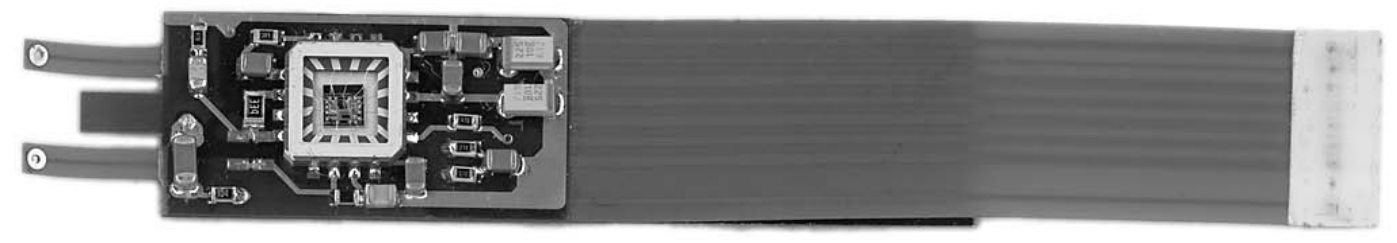

figure 2: multilayer board with kapton flex assembling

This design has been used to study electrical, thermal characteristics and radiation effects. 


\section{Response time}

Figure 3 shows the configuration chosen for a direct coupling with the detector. A dc feedback by Rcontrol locks and stabilizes nodes voltage of the circuit. Add noise is negligible.

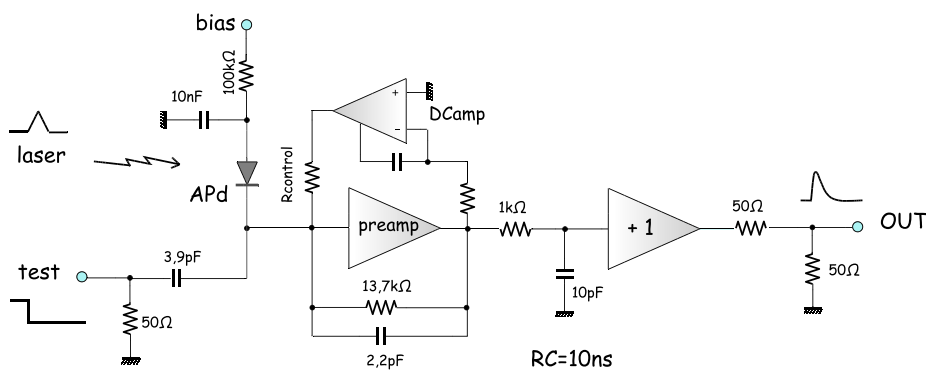

figure 3 : testing configuration

The responses of the different charge injection have been measured with Hamamatsu APD-05 CMS prototype $(\mathrm{Cd} \approx 70 \mathrm{pF})$. Measured transient pulse response on $50 \Omega$ are shown in figure 4. A comparison between nitrogen laser pulse $(337.1 \mathrm{~nm}$, fwhm:3ns) and electrical charges injection $(7.2 \mathrm{pC}$, rise:5ns) have been recorded.

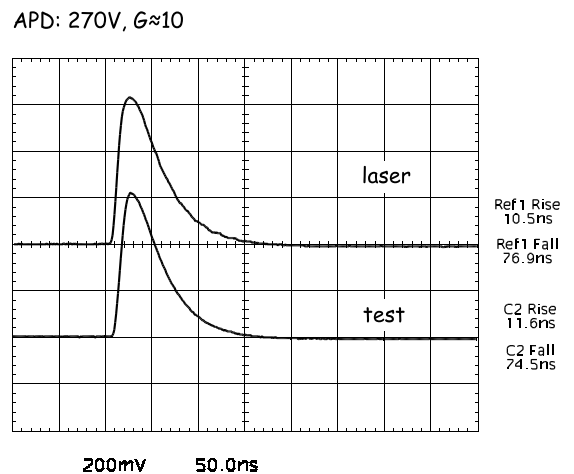

figure 4: output pulse

Charges collection is very fast. In fact the shaping time observed is given by electronic response of integration cell (RC=10ns). 


\subsection{Noise}

Noise has been measured after RC low noise fast shaping amplifier by an rms voltmeter (Fluke 8920A). A digital scope has been also used to measure output pulse amplitude and peaking time. Total collector current value for the input bipolar transistor (two npn transistors connected in parallel) has been fixed to $0.4 \mathrm{~mA}$.

Results are shown in figure 5 as a function of shaping time for three input capacitance values.

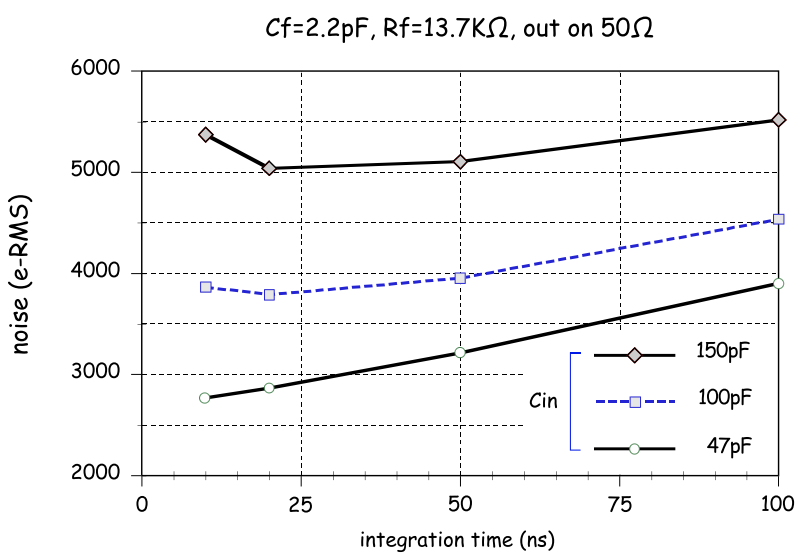

figure 5: noise measurement with external feedback components

Figure 6 presents also the experimental results obtained for three shaping time values as a function of input capacitance.

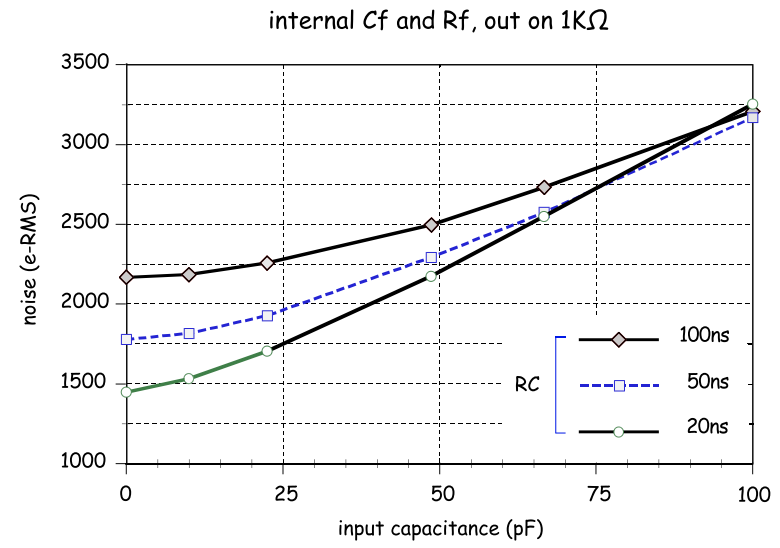

figure 6: noise measurement with only integrated feedback components 


\section{Irradiation tests}

Irradiation test protocole and results obtained with a Xray SEIFERT RP149 generator, equivalent to ARACOR [5], are given up to $10 \mathrm{Mrad}(\mathrm{SiO} 2)$ in CMS note paper ${ }^{[6]}$. The table1 shows the main dc parameters (figure 1 for nodes names) for two circuits $(009,011)$ preamplifiers pre and post radiation five days later.

\begin{tabular}{|c|c|c|c|c|c|}
\hline & \multicolumn{5}{|c|}{$D C$ parameters } \\
\hline & \multicolumn{2}{|c|}{ sample 009} & \multicolumn{2}{|c|}{ sample 011} & \multirow{2}{*}{$\begin{array}{c}\max \\
\text { variation }\end{array}$} \\
\hline & 0 Mrad & $10 \mathrm{Mrad}$ & 0 Mrad & $10 \mathrm{Mrad}$ & \\
\hline IRf & $36 n A$ & $-15 n A$ & $18 n A$ & $-33 n A$ & $50 n A$ \\
\hline Vbe in & $.7290 \mathrm{~V}$ & $.7274 \mathrm{~V}$ & $.7284 \mathrm{~V}$ & $.7268 \mathrm{~V}$ & $1.6 \mathrm{mV}$ \\
\hline Vbe in $B$ & $.7290 \mathrm{~V}$ & $.7252 \mathrm{~V}$ & $.7275 \mathrm{~V}$ & $.7239 \mathrm{~V}$ & $3.7 \mathrm{mV}$ \\
\hline$V_{p}$ & $4.654 \mathrm{~V}$ & $4.651 \mathrm{~V}$ & $4.649 \mathrm{~V}$ & $4.652 \mathrm{~V}$ & $3 \mathrm{mV}$ \\
\hline Vrf & $.7304 \mathrm{~V}$ & $.7269 \mathrm{~V}$ & $.7291 \mathrm{~V}$ & $.7255 \mathrm{~V}$ & $3.55 \mathrm{mV}$ \\
\hline beta dc & $100 \%$ & $81 \%$ & $100 \%$ & $80 \%$ & $20 \%$ \\
\hline
\end{tabular}

Table 1: measured DC parameters

Pre and post radiation electronic noise performance are summarized in table 2 according to input capacitance.

\begin{tabular}{|c|c|c|c|c|}
\hline \multicolumn{2}{|c|}{} & \multicolumn{2}{|c|}{ noise (e-RMS), bandwidth $20 \mathrm{MHz}$} \\
\hline \hline \multicolumn{2}{|c|}{ sample 009 } & \multicolumn{2}{|c|}{ sample 011} \\
\hline & O Mrad & 10 Mrad & O Mrad & 10 Mrad \\
\hline Cin=0pF & 1620 & 1730 & 1650 & 1820 \\
\hline Cin=47pF & 2390 & 2520 & 2440 & 2580 \\
\hline Cin=100pF & 3350 & 3380 & 3390 & 3420 \\
\hline
\end{tabular}

Table 2: measured noise

A small change occured in the noise, $0.9 \%$ at $100 \mathrm{pF}$ input capacitance when a shaping time of $22 \mathrm{~ns}$ is used.

\section{Upgrade}

An upgraded version, LNCP-62, in UHF1X technology has been studied. Perspectives are to improve noise, linearity and better fit for detector. A new DC amplifier allows for current monitoring up to 500 $\mu$ A. A non inverting fast pulse amplifier with voltage gain of eight has been implemented on chip. A 20 pinout ceramic leadless chip carrier LNCP-62 is actually under test. 


\section{Conclusion}

This version 2, LNCP-52, works properly. The performances agree very well with predicted calculations and simulations. Easily able to change from one detector application to another, the circuit is very versatile.

Main characteristics:

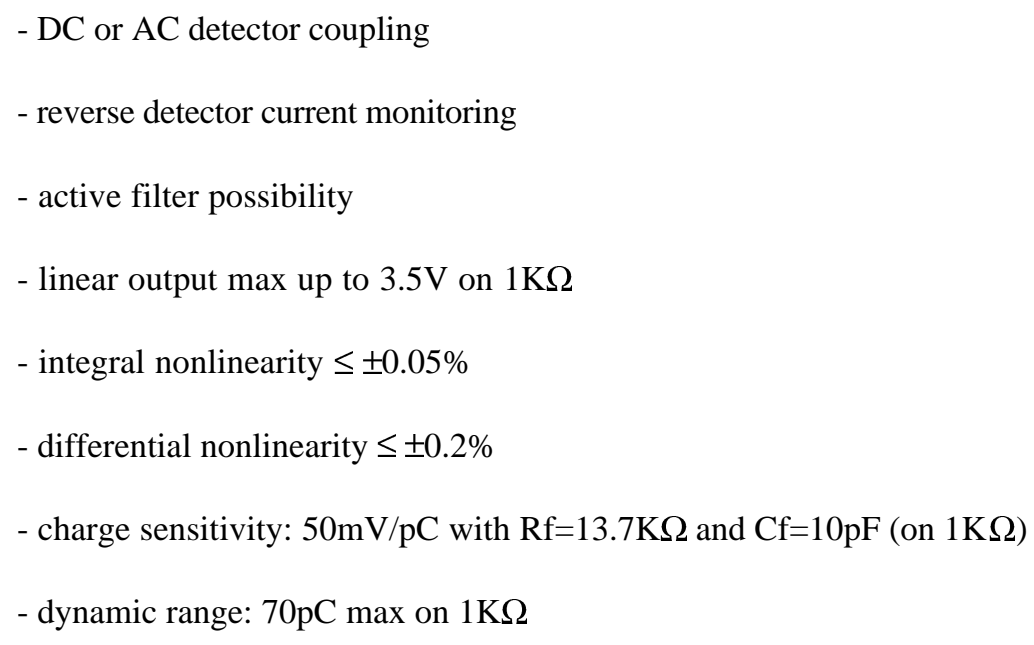

\section{Acknowledgements}

Grateful thanks to SdM team for prototype assistance, CAD support and integrated circuit layout. This work was supported in part by CMS-ECAL collaboration.

\section{References}

[1] Veljko Radeka, Low-Noise Techniques In Detectors, Ann. Rev. Nucl. Part. Sci. 1988,38, 217-277.

[2] E.Gatti and P.F. Manfredi, Processing the signals from solid-state detectors in elementary-particle Physics, Rivista del nuovo cimento, Vol-9, N.1, 1986.

[3] M. Goyot, Second Workshop on Electronics for LHC Experiments, Balaton, CERN/LHCC/96-39

[4] T. Melebeck, SdM, Charleroi, Belgique

[5] L.J. Palkuti, J.J. Lepage, "X-ray wafer probe for total dose testing”, IEEE, Trans. Nucl. Sciences, Vol. NS29, N.6, December 1982, 1832-1837.

[6] M. Goyot, "Irradiation tests on bipolar front-end preamplifier using the Harris UHF1 technology", CMS Note $1997 / 098$ 


\section{Figures caption}

1 - simplified diagram

2 - multilayer board with kapton flex assembling

3 - testing configuration

4 - output pulse

5 - noise measurement with external feedback components

6 - noise measurement with only integrated feedback components

Table1: measured DC parameters

Table2: measured noise 